\title{
In situ reconstruction using the half-ring-shaped aortic wall for transposition of the great arteries
}

Takashi Miyamoto, MD, PhD, Shuichi Yoshitake, MD, Akihiro Sasahara, MD, and Yuji Naito, MD, PhD, Gunma, Japan

From the Department of Cardiovascular Surgery, Gunma Children's Medical Center, Gunma, Japan.

Disclosures: Authors have nothing to disclose with regard to commercial support.

Received for publication Nov 20, 2015; revisions received Feb 23, 2016; accepted for publication March 4, 2016; available ahead of print April 7, 2016.

Address for reprints: Takashi Miyamoto, MD, PhD, 779 Shimohakoda, Hokkitsu, Shibukawa, Gunma 377-8577, Japan (E-mail: yonomiyataka@msn.com).

J Thorac Cardiovasc Surg 2016;152:e29-31

$0022-5223 / \$ 36.00$

Copyright (C) 2016 by The American Association for Thoracic Surgery

http://dx.doi.org/10.1016/j.jtcvs.2016.03.021

The arterial switch operation has evolved as the treatment of choice for most forms of transposition of the great arteries. Despite advancements in the technical aspects of the procedure, certain anatomic variations of the coronary arteries, such as a single coronary orifice and the intramural coronary artery, are still considered surgical risks. We describe a new technique of the arterial switch operation with in situ coronary reconstruction using the half-ringshaped aortic wall.

\section{CLINICAL SUMMARY}

A 16-day-old Japanese girl weighing $2.9 \mathrm{~kg}$ who exhibited whole body cyanosis and desaturation at birth was diagnosed with transposition of the great arteries, atrial septal defect, and patent ductus arteriosus associated with a single coronary artery and an intramural coronary artery pattern. This patient had a single coronary artery that originated from the right sinus (sinus 2), an anterior-posterior great arterial relation, and an intramural left main coronary artery that passed between the great arteries. The coronary artery type anatomy in this case is denoted by Leiden classification as 2R;2AD, Cx (Figure 1, A). After cardioplegic arrest with antegrade cold cardioplegia under moderate hypothermic cardiopulmonary bypass, the root catheter was removed and the ascending aorta was transected distally. The second incision of the aorta was performed with a half-ring-shaped aortic wall of 5-mm width above the commissure. The posterior facing commissure was detached. The pulmonary artery was transected and brought anteriorly to the aorta using the LeCompte maneuver. After careful recognition of the intramural left main coronary artery, we fully unroofed the anterior wall of the intramural course of artery. Subsequently, in situ reconstruction was performed using the half-ring-shaped aortic wall

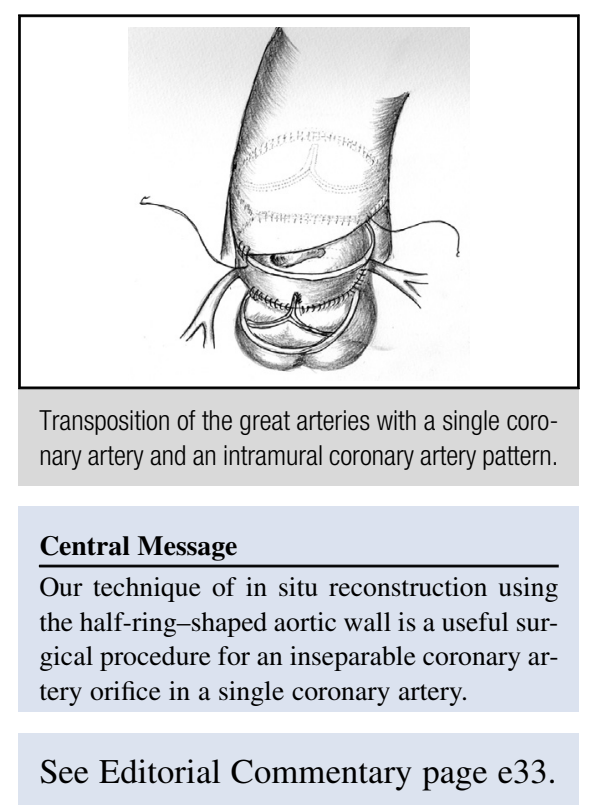

relocated and sutured to the right and left coronary facing sinuses (Figure 1, B). The distal ascending aorta was reanastomosed to the proximal pulmonary artery (neoaorta) (Figure 1,C). After aortic declamping, the defect from the resection of the proximal aorta (neopulmonary artery) to create the button was reconstructed using a U-shaped patch of glutaraldehyde-fixed autologous pericardial patch. After the resuspension of the neopulmonary valve to the adventitial surface of the relocated half-ring of the aorta, a single pericardial patch was sutured to the adventitial surface of the relocated half-ring of the aorta as the neopulmonary arterial posterior wall (Figure 1,D). The child was weaned from cardiopulmonary bypass with low-dose inotropes, and the postoperative course was uneventful. Angiography at 6 months postoperatively revealed a patent coronary neosinus and showed good blood flow into the left coronary system.

\section{DISCUSSION}

The Leiden group emphasized the significance of an intramural course, which often takes a course across the site of attachment of the commissure of the leaflets 

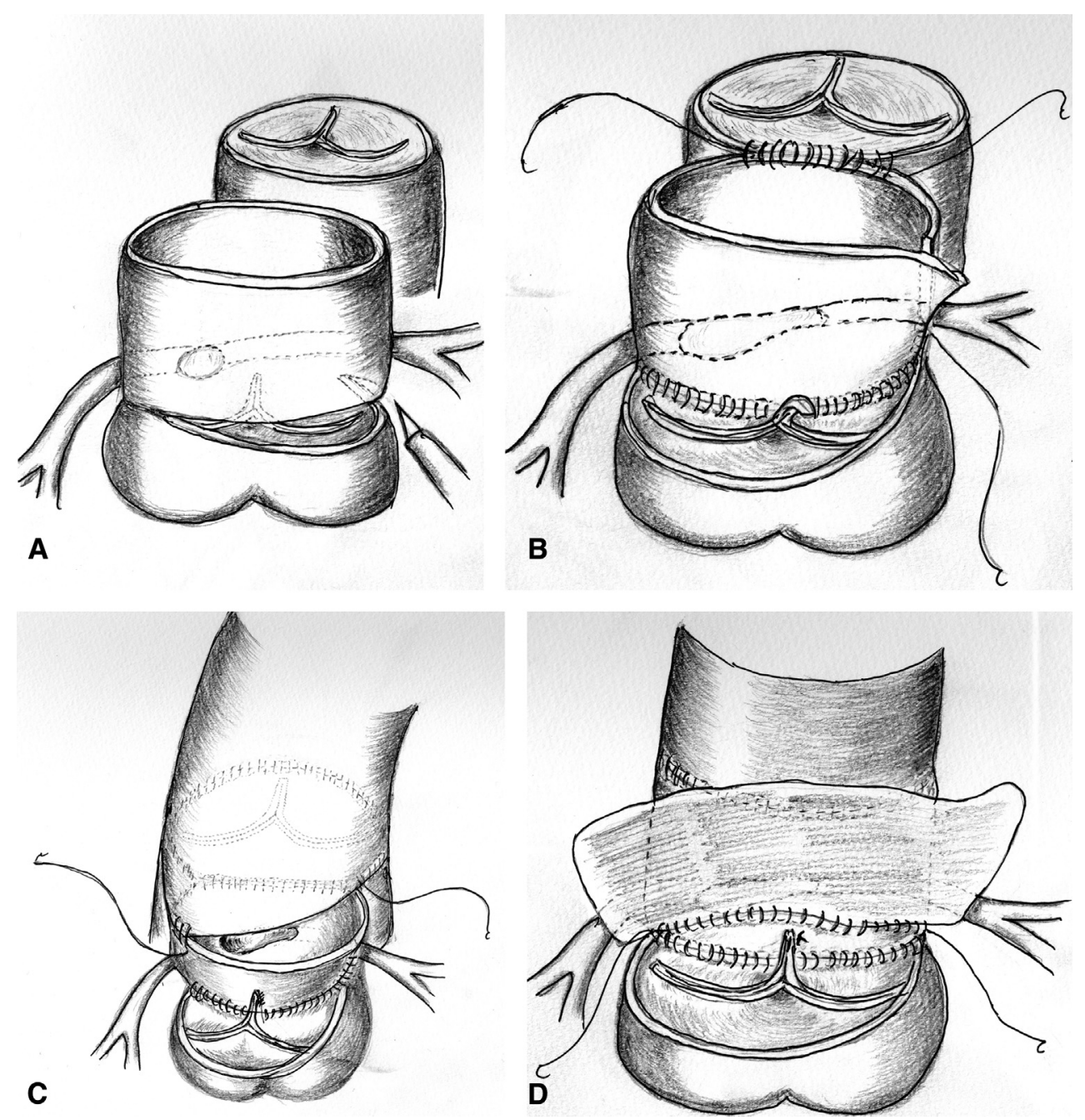

FIGURE 1. A, The coronary artery type anatomy in this case is denoted by Leiden classification: 2 right coronary artery, 2 left anterior descending coronary artery, left circumflex coronary artery. B, Unroofing technique of the intramural coronary artery. Suture technique of the half-ring-shaped aortic wall to the right and left facing coronary sinuses. Detachment of the posterior commissure of the aortic valve. C, Resuspension of the neopulmonary valve commissure to the adventitial surface of the relocated half-ring of the aorta. Reanastomosis of the neoaorta. D, Suture of a single pericardial patch to the adventitial surface of the relocated half-ring of the aorta as the neopulmonary arterial posterior wall.

facing the pulmonary trunk. In addition, the orifice of the intramural coronary often is stenotic, and the artery frequently passes between the aorta and the pulmonary trunk. Relocation of the intramural coronary artery poses significant surgical difficulties; therefore, the method of coronary arteries left in situ may have a useful role in the management of such cases. ${ }^{1}$ Aubert and colleagues $^{2}$ reported a technique by creating an aortopulmonary window and suturing a pericardial patch around the coronary orifice. This led to pericardial patch shrinkage in the long term. ${ }^{2}$ Takeuchi and Katogi $i^{3}$ reported a modification of Aubert and colleagues' technique. They used the great arterial wall to create a tunnel, thereby avoiding the pericardial patch. ${ }^{3} \mathrm{~A}$ modification of Aubert and colleagues' procedure is the Imai method described by Mee, ${ }^{4}$ wherein a hinged nonfacing aortic sinus wall is used as a baffle instead of the pericardial patch. These "coronary artery left in situ procedures" lessen early surgical mortality. However, baffle stenosis and pulmonary artery obstructions due to an oversized intra-arterial baffle and late ostial stenosis can occur, especially in cases of the intramural course; theoretic hazards that may require future revision still remain. In 1994, Asou and colleagues ${ }^{4}$ described a technique to relocate the intramural coronary artery by creating 2 separate buttons. In cases of dividable coronary orifices, the coronary buttons should be translocated in the usual coronary 
transfer after unroofing the intramural course. Although direct implantation of the coronary buttons with 2 separate buttons is considered the best method to repair single-origin orifices with an intramural course of the coronary artery, we decided to perform the method of coronary artery left in situ in this particular case because the distance between the 2 coronary orifices was too short to separate them into 2 buttons. In our technique, the aortic wall was incised in a half-ringshaped fashion above the commissure, the posterior facing commissure was detached, and in situ reconstruction was performed using the half-ring-shaped aortic wall relocated and sutured to the right and left coronary facing sinuses to not injure the neopulmonary valve.

\section{CONCLUSIONS}

The reconstructed cuff size as a new coronary orifice can be larger than that possible with other "left in situ" techniques. Moreover, this procedure provides a satisfactory elongated and wide coronary pathway. Careful follow-up is mandatory. This patient has received regular ambulatory treatment once every 4 weeks, and echocardiography is performed semiannually. On the postoperative angiogram at 6 months, there were no obstructive changes in the coronary system, pulmonary stenosis, or regurgitation in the patient described. In these types of cases, our technique of in situ reconstruction using the half-ring-shaped aortic wall is a useful surgical procedure for an inseparable coronary artery orifice in a single coronary artery when the intramural main coronary artery passes between the great arteries.

The authors thank Kenichi Takahashi for editing the figures.

\section{References}

1. Suzuki T. Modification of the arterial switch operation for transposition of the great arteries with complex coronary artery patterns. Gen Thorac Cardiovasc Surg. 2009:57:281-92.

2. Aubert J, Pannetier A, Couvelly P, Unal D, Rouault F, Delarue A. Transposition of the great arteries: new technique for anatomical correction. Br Heart J. 1978;40: 204-8.

3. Takeuchi S, Katogi T. New technique for the arterial switch operation in difficult situations. Ann Thorac Surg. 1990;50:1000-1.

4. Mee RB. The arterial switch operation. In: Stark J, de Leval M, eds. Surgery for Congenital Heart Defects. 2nd ed. Philadelphia, PA: WB Saunders; 1994: 483-500. 